\title{
Anatomical variations of the sphenoid sinus \\ - a study of 200 cases -
}

1"Ovidius" University of Constanta, Faculty of Medicine

${ }^{2}$ UMF „Carol Davila” Bucuresti, Faculty of Medicine

\begin{abstract}
Our study on the anatomical variation of pneumatisation of the sphenoid sinuses was performed on 200 tomographical studies, evaluating the anatomical variations of the sphenoid sinuses and the Onodi cells, the types of pneumatisation according with the types described by Hammer and Radberg, as well as the extensions of pneumatisation towards the anterior clinoid processes, pterygoid processes and sphenoidal wings; the frequency of intrasphenoidal protrusions and dehiscences of internal carotid artery, optic nerve, Vidian canal and foramen rotundum and the presence of primary and secondary septa attached to their canals.
\end{abstract}

Keywords: sphenoid sinus, anatomical variations

\section{Lupascu Mihai M.D.}

Bld Ferdinand 53, Bl A8, Sc, B, Ap. 45

Constanta, Romania

Tel.: +40745050439

e-mail:dr_lupa@yahoo.com

\section{Introduction}

Modern endoscopic sinus surgery has similar if not greater perils as classic sinus surgery. The many pitfalls of intrasphenoidal surgery are mainly due to the proximity of vital structures such as the internal carotid artery (ICA), as well as structures whose injury would create a permanent disability to the patient, such as the optic nerve $(\mathrm{ON})$. These risks increase in case of absence of normal endoscopic anatomy, as in the case of surgical reinterventions.

The sphenoid sinus is considered the most variable of the paranasal sinuses [1] in terms of degree and type of pneumatisation, number and position of intra and intersinus septa, relation with the surrounding surgical risk elements: the II, III, IV, V, VI and Vidian nerves, the ICA inside the cavernous sinus and the pituitary gland [2].

The scope of the study is to minimize the risk of surgery and decrease surgical morbidity through 
better understanding of anatomy and the degree of anatomical variation of the sphenoid sinus.

There are considerable variations regarding the anatomy of the sphenoid sinus as noted by many authors in their cadaver and computed tomography studies [2-6], some authors finding variations among different races as well [7].

\section{Materials and methods}

We studied 200 CT examinations of the paranasal sinuses (400 sides), taken between January 2011 and March 2012 at Medimar Imagistic Services Constanța by patients with diverse ENT, neurological and neurosurgical pathology, using a GE Brightspeed 16 slices CT scanner with a thickness of $5 \mathrm{~mm}$ acquisition with reconstruction of $1,5 \mathrm{~mm}$ with a window of 2000-300 HU.

The two sphenoid sinuses were measured separately taking into account the greatest lengths in all three dimensions (length, height and width).

We analysed the examinations in 3 dimensions, using three-dimensional reconstructions based on series of coronal and axial sections $3 \mathrm{~mm}$ apart, evaluating:

1. the anatomical variations of the sphenoid sinuses and the Onodi cells;

2. the types of pneumatisation according with the types described by Hammer and Radberg [3], as well as the extensions of pneumatisation towards the anterior clinoid processes (ACP), pterygoid processes and sphenoidal wings;

3. the frequency of intrasphenoidal protrusions and dehiscences of ICA, ON and the presence of primary and secondary septa attached to their canals [4].

In accordance with [3], the sphenoid sinuses were either part of:

- conchal type, when the sinus is separated from the sella by thick trabecular bone;

- presellar type, when the sinus is pneumatised without extending posteriorly of the sellar floor;
- sellar type, when the sinus extends inferiorly and posteriorly of the sella turcica.

\section{Results}

The mean age of the patients at the time of the study was 48.5 , varying between the ages of 15 and $80,116(58 \%)$ of the patients were men and $84(42 \%)$ were women.

Out of the 400 sinuses that we measured 138 $(69 \%)$ were sellar type, $56(28 \%)$ were of presellar type, the conchal type being found in only $6(3 \%)$ sinuses. (Figure 1)

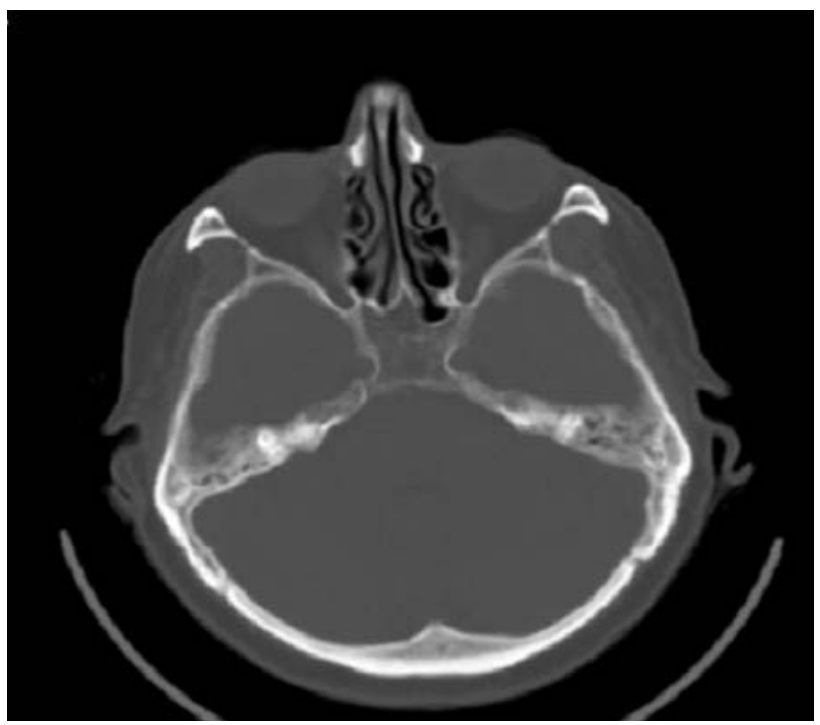

Figure 1 - Conchal type sphenoid sinuses in 37 year old female patient

The mean dimensions of the sinuses were 24/20.5/18 $\mathrm{mm}$, mean dimensions in men being 23.4/22.1/19.2 $\mathrm{mm}$ and 24.5/18.6/17.1 $\mathrm{mm}$ in women, with no significant differences between left and right.

In $33 \%$ of the cases we found extensive pneumatisation of the pterygoid process, in $10 \%$ of the cases the anterior clinoid processes were pneumatised forming deep optico-carotic recesses and in $8 \%$ of the cases there were lateral extensions of pneumatisation 
in the lesser and greater sphenoidal wings. (Figure 2) Onodi sphenoethmoidal cells were found in $18 \%$ of the cases, usually associated with smaller sized sphenoid sinuses.

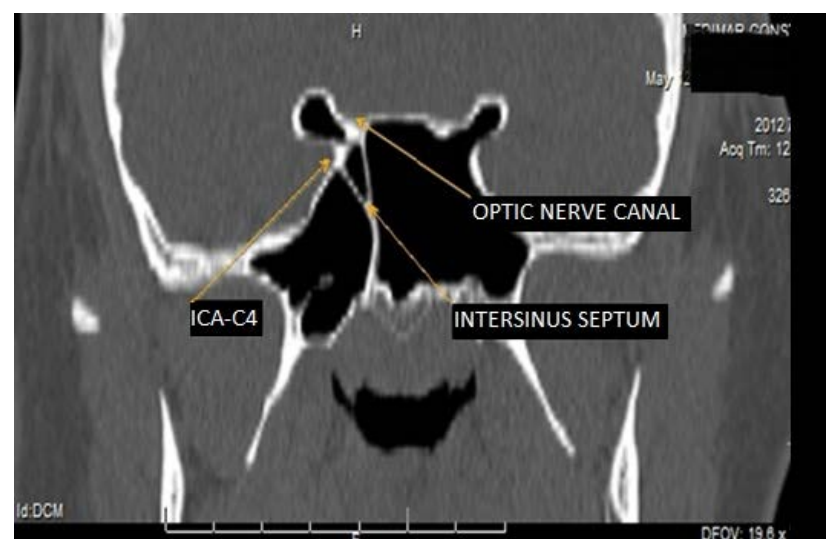

Figure 2 - Pneumatised pterygoid and anterior clinoid processes with intersinus and secondary septa anchored on both optic nerve canal and internal carotid artery protrusion

The ICA gave intrasphenoidal protrusions in $55 \%$ of cases in the C3 segment and in 57\% of cases in $\mathrm{C} 4$ segment, in only $2 \%$ of cases there were evident dehiscent parts. (Figure 3) The optic nerve had protrusions in $65 \%$ of cases, its canal having dehiscent parts in $5 \%$ of cases. (Figure 4 ), in 3 cases being completely dehiscent in only 3 cases $(0.75 \%)$. We have found protrusion of the Vidian canal in $16 \%$ of cases and of the foramen rotundum in $7 \%$ of cases.

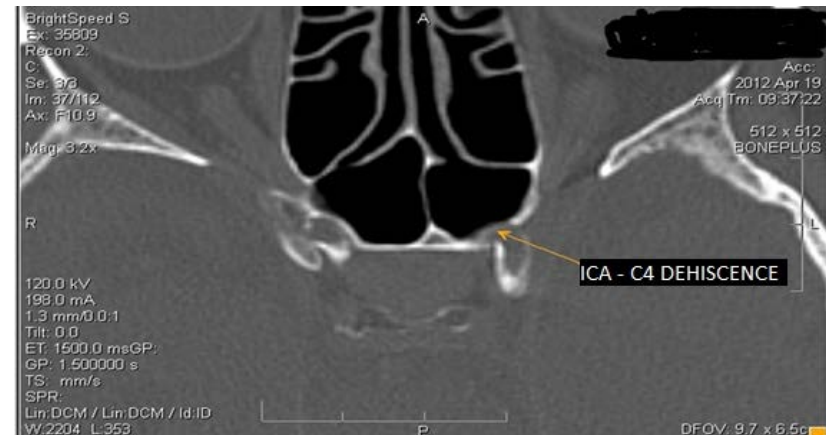

Figure 3 - Dehiscence of the internal carotid artery in the C4 part

The intersinusal septum was situated on or close to the midline in only $38 \%$ of the patients, also there was a $47 \%$ incidence of secondary intrasinusal septa. An aspect of particular surgical importance is that in $32 \%$ of cases either the main septum or the secondary septa had insertions on the optic nerve canal or the bone covering the internal carotid artery.

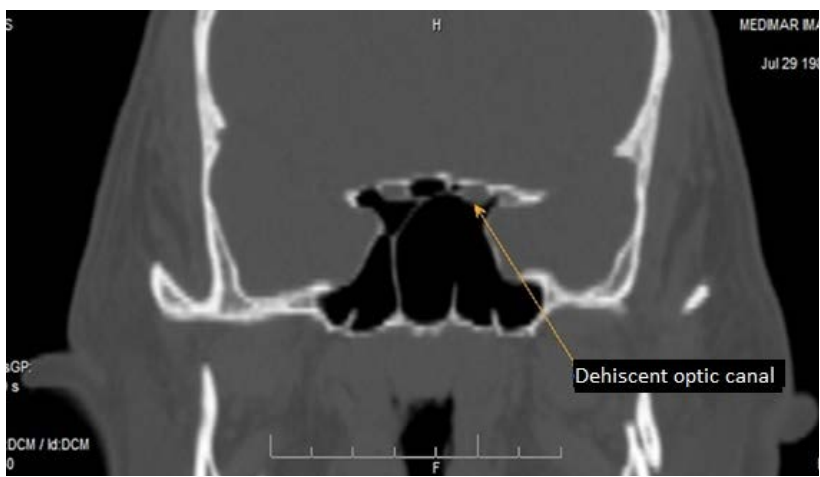

Figure 4 - Dehiscence of the optic canal with secondary septum anchored on contralateral canal.

\section{Discussion}

The incidence of the sellar type of pneumatisation in literature is found in $53-89 \%$ of cases, the presellar type in 10-38\% and the conchal type in $0-9 \%$, in our study the sellar type was as well, most frequently found, in $69 \%$ of the cases, above the percentage found in the studies of Hamid et al. [7] (55\%) and Araújo Filho et al. [8] (53\%), but much lower than in the studies of Kinnman [5] (87\%) and [3] $(86 \%)$. The conchal type was found in only $3 \%$ of the cases, this type of pneumatisation has an increased surgical risk in transsphenoidal surgery because of the amount of bone that needs to be drilled, even when guided by neuronavigation, some authors considering this type of pneumatisation a counter indication for transsphenoidal approach to the pituitary gland.

We have found that the intersinusal septum divides the sphenoid body in two almost equal cavities in $38 \%$ of the cases, having secondary septa in $47 \%$ of the cases, compared to [3], who finds the intersinusal septum forms two equal cavities in $27 \%$ 
Table I - Frequency of extensions of pneumatisation

\begin{tabular}{|l|c|c|c|c|}
\hline & $\begin{array}{c}\text { Pterygoid } \\
\text { processes }\end{array}$ & $\begin{array}{c}\text { Anterior clinoid } \\
\text { processes }\end{array}$ & Sphenoid wings & Ononi cells \\
\hline Lupașcu & $33 \%$ & $10 \%$ & $8 \%$ & \\
\hline Elwany et al. & $15.5 \%$ & $41.9 \%$ & $31.7 \%$ & \\
\hline Kazkayasi et al. & $30.7 \%$ & $12.9 \%$ & & $2.6 \%$ \\
\hline Araújo Filho et al. & $50 \%$ & $54 \%$ & $47.6 \%$ & $31 \%$ \\
\hline $\begin{array}{l}\text { Kainz \& } \\
\text { Stammberger }\end{array}$ & - & - & - & $42 \%$ \\
\hline
\end{tabular}

of cases, having a vertical direction in $25 \%$ of cases, [5] finds the septum on the midline in $42 \%$ of cases with secondary septa in $19 \%$ of cases, meanwhile Zada et al. [9] finds a single septum situated on the midline in $18.5 \%$ of cases and a complex endosinus anatomy with multiple secondary septa in $29 \%$ of the cases, Kazkayasi et al. [10] in 19.5\%, [8] in $23.8 \%$.

Sareen et al. [11] found secondary septa in up to $80 \%$ and Fernandez-Miranda et al. [12] consider that, when present, in up to $87 \%$ of the cases, at least one of the secondary septa is inserted on the protrusion of the ICA, we have found this aspect in only $32 \%$ of the cases.

We have found extensions of pneumatisation in the pterygoid processes in $33 \%$ of the cases, this type of extension being correlated with protrusion of the Vidian nerve, the results being similar to [10] $(30.6 \%)$, but much lower than [8] (50\%), in $10 \%$ of the cases the anterior clinoid processes were well pneumatised , forming deep opticocarotic recesses, the results being similar to [10] and, again, much lower than [8] (54\%) and Elwany et al. [13] (41.9\%), the sphenoidal wings were pneumatised in only $8 \%$ of the cases, much lower than the results of the studies of [13] and [8], with $31.7 \%$, respectively $47.6 \%$ (Table I).

In $18 \%$ of the cases we have found Onodi sphenoethmoidal cells, named after the esteemed Hungarian anatomist, the presence of these cells holding great practical importance, their presence increasing the risk of surgical lesion of the O.N. There are great variations in literature regarding this type o cells, Mutlu et al. [14] finding them in $7.2 \%$ of cases, [10] in $2.6 \%$, meanwhile Kainz and Stammberger [15] report an incidence of $42 \%$ and Tomovic et al. [6] find them in up to $65.3 \%$, the latter finding variation between races as well, in Asians, the incidence reaching $83 \%$.

The prevalence of the ICA and ON protrusions in our study is superior to that found by [13], [10] and Unal et al. [16], similar to the findings of [8], but much lower compared to the findings of Fujii et al. [2] (Table II).

The prevalence of dehiscence inside the sphenoid sinus of the ICA and the ON is similar

Table II - Incidence of protrusions and dehiscences of neurovascular structures

\begin{tabular}{|l|c|c|c|c|c|c|}
\hline & ICA & $\begin{array}{c}\text { ICA } \\
\text { dehiscence }\end{array}$ & ON & $\begin{array}{c}\text { ON } \\
\text { dehiscence }\end{array}$ & $\begin{array}{c}\text { Vidian } \\
\text { canal }\end{array}$ & $\begin{array}{c}\text { Maxilary } \\
\text { nerve }\end{array}$ \\
\hline Lupașcu & $68.3 \%$ & $2 \%$ & $65 \%$ & $5 \%$ & $16 \%$ & $7 \%$ \\
\hline Elwany et al. & $18.2 \%$ & $4.8 \%$ & $29 \%$ & $0 \%$ & $7.5 \%$ & $12.9 \%$ \\
\hline Heskova et al. & - & - & $35.3 \%$ & $11.7 \%$ & - & - \\
\hline Kazkayasi et al. & $5.2 \%$ & $1.5 \%$ & $4.1 \%$ & $0.7 \%$ & $36.7 \%$ & $14.2 \%$ \\
\hline Araújo Filho et al. & $48.8 \%$ & $32.1 \%$ & $36.9 \%$ & $9.1 \%$ & $45.4 \%$ & $49.8 \%$ \\
\hline Unal et al. & $26.5 \%$ & $4.7 \%$ & $27.3 \%$ & $7 \%$ & $31.1 \%$ & $26.5 \%$ \\
\hline Fujii et al. & $98 \%$ & $8 \%$ & $94 \%$ & $4 \%$ & - & - \\
\hline
\end{tabular}


to most studies, but the prevalence of Vidian and maxillary protrusion is much lower than [10], [8] and [16] and similar to the results of the study of [13].

\section{Conclusions}

The sphenoid sinuses have a remarkable variation in form, dimension and position relative to the surrounding neurovascular structures, knowing tis relations before surgery may prove to be the difference between surgical success and fatal complications.

The presurgery imagistic examinations should be evaluated systematically punctuating all elements of surgical risk and evaluating the degree of pneumatisation, protrusion of the surrounding elements and more importantly the dehiscence of the bony walls covering them, found relatively rare in the population, but potentially lethal during surgery.

A particular element of surgical risk is the Onodi cells, found in $18 \%$ of the cases, the risk of injuring the optic nerve through transethmoidal approach of the sphenoid sinus increasing greatly in their presence.

\section{References}

1. Budu, V., Mogoantă, C. A., Fănuță, B. \& Bulescu, I. (2013). The anatomical relations of the sphenoid sinus and their implications in sphenoid endoscopic surgery. Romanian journal of morphology and embryology $=$ Revue roumaine de morphologie et embryologie. 54(1), 13

2. Fujii, K., Chambers, S. M. \& Rhoton, Jr A. L. (1979). Neurovascular relationships of the sphenoid sinus: a microsurgical study. Journal of neurosurgery. 50(1), 31-39

3. Hammer, G. \& Rådberg, C. (1961). The sphenoidal sinus. Acta Radiologica [Old Series], 56(6), 401-422.

4. Zimmerman, A.A. (1938). The development of the paranasal sinuses. Ann Otol Rhinol Laryngol. 47, 1112-1116.

5. Kinnman, J. (1977). Surgical aspects of the anatomy of the sphenoidal sinuses and the sella turcica. Journal of anatomy. 124(Pt 3), 541

6. Tomovic, S., Esmaeili, A., Chan, N.J., Choudhry, O.J., Shukla, P.A., Liu, J.K. \& Eloy, J.A. (2012). High-resolution computed tomography analysis of the prevalence of onodi cells. The Laryngoscope. 122(7), 1470-1473.

7. Hamid, O., El Fiky, L., Hassan, O., Kotb, A. \& El Fiky, S. (2008). Anatomic variations of the sphenoid sinus and their impact on transsphenoid pituitary surgery. Skull base. 18(1), 9.

8. Araújo Filho, B.C., Neto, C.P., Weber, R. \& Voegels, R.L. (2008). Sphenoid sinus symmetry and differences between sexes. Rhinology. 46(3), 195-199.

9. Zada, G., Agarwalla, P.K., Mukundan, Jr S., Dunn, I., Golby, A.J. \& Laws, Jr E.R. (2011). The neurosurgical anatomy of the sphenoid sinus and sellar floor in endoscopic transsphenoidal surgery: Clinical article. Journal of neurosurgery. 114(5), 1319-1330.

10. Kazkayasi, M., Karadeniz, Y. \& Arikan, O.K. (2005). Anatomic variations of the sphenoid sinus on computed tomography. Rhinology. 43(2), 109-14.

11. Sareen, D., Agarwal, A.K., Kaul, J.M. \& Sethi, A. (2005). Study of sphenoid sinus anatomy in relation to endoscopic surgery. Int $J$ Morphol. 23(3), 261-266.

12. Fernandez-Miranda, J.C., Prevedello, D.M., Madhok, R., Morera, V., Barges-Coll, J., Reineman, K. \& Kassam, A.B. (2009). Sphenoid septations and their relationship with internal carotid arteries: anatomical and radiological study. The Laryngoscope. 119(10), 1893-1896.

13. Elwany, S.A.M.Y., Eisaeld, I. \& Thabet, H. (1999). Endoscopic anatomy of the sphenoid sinus. Journal of laryngology and otology. 113(2), 122-126. 
14. Mutlu, C., Unlu, H.H., Goktan, C., Tarhan, S. \& Egrilmez, M. (2001). Radiologic anatomy of the sphenoid sinus for intranasal surgery. Rhinology. 39(3), 128-132.

15. Kainz, J. \& Stammberger, H. (1992). Danger areas of the posterior rhinobasis: an endoscopic and anatomical-surgical study. Acta otolaryngologica. 112(2), 852-861.
16. Unal, B., Bademci, G., Bilgili, Y.K., Batay, F. \& Avci, E. (2006). Risky anatomic variations of sphenoid sinus for surgery. Surgical and Radiologic Anatomy. 28(2), 195-201. 